\title{
Quality of life in patients with chronic wounds: magnitude of changes and predictive factors
}

\author{
Calidad de vida en pacientes con heridas crónicas: magnitud \\ de los cambios y factores predictivos \\ Qualidade de vida de pessoas com feridas crônicas: \\ magnitude das mudanças e fatores preditivos
}

Vera Lúcia Conceição de Gouveia Santos ${ }^{1}$, Alcicléa dos Santos Oliveira², Ana Flávia dos Santos Amaral ${ }^{3}$, Erika Tihemi $\mathrm{Nishi}^{4}$, Jaqueline Betteloni Junqueira ${ }^{5}$, See Hee Park Kim ${ }^{3}$

How to cite this article:

Santos VLCG, Oliveira AS, Amaral AFS, Nishi ET, Junqueira JB, Kim SHP. Quality of life in patients with chronic wounds: magnitude of changes and predictive factors. Rev Esc Enferm USP. 2017:51:e03250. DOI: http://dx.doi.org/10.1590/S1980-220X2016049603250

${ }^{1}$ Universidade de São Paulo, Escola de Enfermagem, Departamento de Enfermagem Médico-Cirúrgica, São Paulo, SP, Brazil.

${ }^{2}$ Hospital Beneficiência Portuguesa, São Paulo, SP, Brazil.

${ }^{3}$ Universidade de São Paulo, Escola de Enfermagem, São Paulo, SP, Brazil.

${ }^{4}$ Universidade de São Paulo,

Faculdade de Medicina, Hospital das Clínicas, São Paulo, SP, Brazil.

${ }^{5}$ Universidade de São Paulo, Hospital Universitário, São Paulo, SP, Brazil.

\begin{abstract}
Objective: To assess health-related quality of life, its predictors and magnitude of changes in health-related quality of life in patients with chronic wounds receiving specialized outpatient treatment. Method: Secondary, retrospective, descriptive, quantitative study with patients with chronic wounds from two specialized outpatient services in Brazil assessed through Ferrans \& Powers Quality of Life Index-Wound Version, Visual Analog Pain Scale, Global Assessment Scale, Pressure Ulcer Scale for Healing, sociodemographic and clinical questionnaires at baseline and after 60 days of treatment. Data were analyzed by ANOVA, Spearman Coefficient, Mann-Whitney test and multivariate logistic regression. Results: Twenty-seven patients participated in the study. The overall health-related quality of life scale, health and functioning subscale and socioeconomic subscale scores increased after 60 days of treatment compared to baseline. Pain reduction was a predictor of changes in overall health-related quality of life score as well as religious practice in the family subscale. $92.6 \%$ patients perceived moderate to extensive changes in health-related quality of life. Conclusion: there was improvement of health-related quality of life for the sample studied in the period; pain and religious practice have emerged as predictors of changes in health-related quality of life.
\end{abstract}

\section{DESCRIPTORS}

Quality of Life; Wounds and Injuries; Pain; Religion; Nursing Care.
Corresponding author:

Vera Lúcia Conceição de Gouveia Santos

Avenida Dr. Enéas de Carvalho

Aguiar, 419 - Cerqueira César

CEP 05403-000 - São Paulo, SP - Brazil

veras@usp.br
Received: 01/19/2017

Approved: 04/13/2017 


\section{INTRODUCTION}

Chronic wounds are among health conditions which the patient may suffer for several years, often causing impairment of work activities that results in early retirement and restrictions in daily living and leisure activities ${ }^{(1-4)}$, thus reducing the quality of life (QoL) at any stage of the life cycle and across all life domains ${ }^{(2)}$. Chronic wounds lead to feelings of frustration, anxiety, isolation, depression, low self-esteem, and negative self-concept, thus reducing the QoL of patients ${ }^{(1,4)}$.

The way patients experience their lives, deal with the problem, and perceive family support are challenges faced by nurses. Emotions and thought patterns emerge as key determinants of overall healt ${ }^{(5)}$. Thus, the assessment of health-related quality of life (HRQoL) is an important way for evaluating the results of health interventions by focusing on biopsychosocial needs in search of improved living conditions ${ }^{(6)}$.

There are numerous definitions of HRQoL that include fundamental ideas. The concept should indicate whether the health status measured or estimated is relatively desirable ${ }^{(7)}$. The assessment of HRQoL is an attempt to quantify the consequences of diseases and treatments, according to the subjective perception of patients ${ }^{(8)}$.

For the purpose of this study, QoL is defined as “a person's sense of well-being that stems from satisfaction or dissatisfaction with the areas of life that are important to him/her", as proposed by the authors of the instrument ${ }^{(9)}$. This theoretical framework laid the foundation of Ferrans and Powers Quality of Life Index (FPQLI) $)^{(10)}$, a generic instrument for evaluating QoL, from which specific versions have been created, including the FPQLI-Wound version (FPQLI-WV) ${ }^{(11)}$.

Under the premise that only the individual can measure his QoL, based on his/her own values and preferences, the Minimal Important Difference (MID) for HRQoL becomes an important concept for both the patients and health professionals, as it is based primarily on the patient perception $^{(12)}$. For the patient, the MID can be defined as the minimally significant reduction in symptoms and improvement in function, while for health professionals, it indicates a significant therapeutic effect or change in the prognosis of the disease, which allows the evaluation of the intervention results ${ }^{(13)}$.

In Brazil, there are only few studies that used the FPQLI-WV as well studies using MID to evaluate HRQoL in wound treatment. Knowing the multidimensional and multifactorial nature of QoL, it is critical to involve and value the patient's perception of his condition for the professional.

Therefore, the study aims to assess HRQoL, its predictors and magnitude of changes in HRQoL in patients with chronic wounds receiving specialized outpatient treatment.

\section{METHOD}

This is a retrospective, descriptive and secondary study with quantitative approach which analyzed the data of a doctoral dissertation in nursing ${ }^{(14)}$ about the responsiveness of the FPQLI-WV in patients with chronic wounds. The patients were selected from two public outpatient woundcare clinics specialized in enterostomal therapy $(\mathrm{ET}) /$ wound ostomy and continence (WOC) care in the cities of São Paulo and Manaus (Brazil). Both services have systematized care protocols for the management of patients with wounds, which is coordinated and carried out by ET/ WOC nurses.

The study was approved by the Research Ethics Committees of the School of Nursing, University of São Paulo (approval no. 929/2010 - Attachment A) and São Paulo Hospital (approval no. 044/10 - Attachment B) and authorized by the Nursing Service of the Hospital of Manaus.

Eligibility criteria included: patients older than 18 years of both genders with chronic wounds, physical and mental conditions to respond to the interview, who attended the treatment without interruption and referred for specific outpatient wound treatment. Patients with wounds of neoplastic etiology, acquired immunodeficiency syndrome and extensive burns were excluded, since those are high-impact conditions on people's lives and may interfere in the meaning of the wound in HRQoL ${ }^{(11)}$.

Fifty-nine patients were eligible for the study, but 32 of them failed to complete the study, which required a followup period of 60 days, then were excluded from sample. In most cases, patients dropped out from the study due to some of them live in other municipalities with difficulties to follow up the treatment and others were already in the final stage of wound healing. Thus, the non-probability convenience sample was composed of 27 patients. The power of the tests to analyze the effect difference in HRQoL was $70.5 \%$ (5\% significance level).

After the approval of the Ethics and Research Committee and authorization of the Nursing Service, the ET/WOC nurses involved in the data collection process were submitted to a qualification for patient selection and application of the instruments. After the training, the nurses recruited the patients enrolled in the services confirming the inclusion and exclusion criteria presenting to the participants the study, its objective and procedures, and requested signing of the Informed Consent Term. The information regarding the clinical conditions of the patients was obtained from the patient's medical record. The data were collected from October 2010 to October 2011. The patients were followed up for 60 days and treated by WOC nurses with appropriate topical treatments for their wounds according to the institutions protocols.

In Brazil, at the time of the research, there were not many specialized services with well-defined and organized wound treatment protocols with presence of ET/ WOC nurse. In both services it was observed the existence of protocols but with different standardized resources. Even with different protocols, the most important issue was to evaluate the QoL of patients when they were treated at an unit with systematized care. Different from other public services, both services of this study were specialized and were coordinated by ET/ WOC nurses with a systematized care with evaluation, nursing prescription, follow-up and evolution of the wounds. The patient attendance happened every 7 days.

The sociodemographic characteristics data obtained at baseline were: age, gender, marital status, number of children, religious practice, education level, profession, current job, monthly income, and number of dependents. Clinical 
characteristics obtained were: diseases presented (obesity, diabetes, systemic arterial hypertension, high cholesterol, cardiovascular disease, peripheral vascular disease); medications in use; quantity of medicine in use; current number of wounds; type of wound: venous ulcer, pressure ulcer, dehiscence, diabetic, arterial, mixed, venous ulcer, others; wound time; wound location; wound stage; pain intensity: at the time of the procedure, and the worst and best pain in the last week. These answers were obtained using a semi-structured questionnaire and the data were supplemented with information from medical records, when needed.

Wound characteristics (number of wounds, type of wound, duration, location and stage of the wound, and pain intensity) and HRQoL were assessed through physical examination and interviews, using the Pressure Ulcer Scale for Healing (PUSH) tool ${ }^{(1)}$, a Visual Analog Scale (VAS) for pain ${ }^{(15)}$, the FPQLI-WV ${ }^{(11)}$ and the Global Assessment Scale ${ }^{(14,16)}$, respectively, at admission (baseline) and after 60 days of treatment (endpoint).

FPQLI-WV was the instrument used to assess HRQoL. It has 35 items grouped into two parts: one evaluates life satisfaction and other is related to the importance attached by the individual to aspects of life. Items are divided into four subscales: health/functioning (HF), psychological/spiritual (PS), socioeconomic (SE) and family ( $\mathrm{Fa}$ ). The overall HRQoL score ranges from 0 to 30 where 0 corresponds to the worst HRQoL and 30 to the best HRQoL. For classification, the study of development and validation of instrument ${ }^{(11)}$ was used in this study, in which incremental changes in the score indicate the level of HRQoL, as follows: 24 to $30=$ very good; 18 to $24=$ good; 12 to $18=$ regular; 6 to 12 $=$ poor; and 0 to $6=$ very poor.

The Global Assessment Scale was used to assess changes in HRQoL, as perceived by the patient, related to the wound conditions after 60 days of treatment. The following question was asked: "How is your wound since your last clinical interview?" For analysis purposes, the classification of changes was: $0=$ no change; $+1,+2,-1,-2=$ small change; $+3,+4,-3$, $-4=$ moderate change; and $+5,-5=$ extensive change ${ }^{(14)}$. This classification was also used when analyzing wound healing rates and the worst pain experienced in the past week, as anchors for determining the MID.

Associations of FPQLI-WV scores with other variables were tested using the classical and paired Student's t-tests. Comparisons between variables with more than two factors were made with the analysis of variance (ANOVA) F-test. The Spearman correlation coefficient was used to determine correlation between overall HRQoL scores and continuous variables ${ }^{(17)}$. The parametric Mann-Whitney test was performed to test for associations of discrete variables with FPQLI-WV subscale scores. All independent variables were initially assessed with univariate logistic regression at a significance level of $P \leq 0.10$. Significant variables by univariate analysis were included into a multivariate logistic regression model. In a regression model, the intercept is the mean variation of the value of the dependent variable when the independent variable does not change. Goodness of fit was measured by the adjusted coefficient of determination $\left(R^{2}\right)^{(18)}$.
All statistical tests were performed at a significance level of $5 \%$, except the univariate logistic regression for which the significance level was set at $10 \%(P \leq 0.10)$. Data are expressed as mean \pm standard deviation (SD).

Effect size (ES) was used to evaluate the magnitude of changes in HRQoL. It was calculated assuming that the groups were homogeneous at baseline and had similar standard deviations of the mean ${ }^{(19)}$ and was classified as small (0.20 to 0.49$)$, medium (0.50 to 0.79$)$ and large ${ }^{(12,20)}$, according to changes in HRQoL.

In addition, change in HRQoL during the study period was evaluated under the patient's perspective using MID, which is calculated based on the difference in mean values of the variable in question between baseline and endpoint. In this study, the MID was applied to the results of the Global Assessment Scale, which was used to assess changes in the rate of wound healing and pain intensity.

\section{RESULTS}

Twenty-seven patients participated in the study, 16 (59.2\%) of them were men, the mean age was $50(\mathrm{SD}=12.5)$ years; $55.6 \%$ were employed; $51.8 \%$ married or living with a partner; $55.5 \%$ practicing a religion, and 7.4 mean years of education. Also, $44 \%$ of patients had diabetes; $33.3 \%$ hypertension; $22.2 \%$ dyslipidemia, $92.5 \%$ reported regular use of medication; $85.2 \%$ had a single wound, $11.1 \%$ two wounds, and $3.7 \%$, three wounds. Venous disease (48.1\%) and diabetes $(29.6 \%)$ were the most prevalent causes of the wounds.

The mean overall HRQoL scores were 21.3 at baseline and 24.2 at endpoint, indicating increase in HRQoL after 60 days of treatment. Significant differences of large magnitude were found in $\mathrm{ES}$ on overall $\mathrm{HRQ} \mathrm{OL}$ score $(\mathrm{ES}=1.011)$ and health/functioning $(\mathrm{ES}=1.218)$ and socioeconomic $(\mathrm{ES}=$ 0.765 ) subscale scores (Figure 1).

The variables religious practice, cardiovascular disease and obesity $(P<0.05)$, as well as worst pain experienced in the past week and age $(P \leq 0.10)$ were statistically significant in univariate analysis, and therefore included into the multivariate logistic regression model.

The increase in overall HRQoL and health/functioning, socioeconomic, psycological/spiritual subscale scores on the FPQLI-WV was associated only with a reduction in the worst pain experienced in the past week $(P<0.05)$, explaining $36 \%, 34 \%, 52 \%$ and $28 \%$, respectively, of the variance in differences in HRQoL between baseline and endpoint. In the family subscale, religious practice was an important predictor of change in HRQoL, explaining $30 \%$ of the variance.

The mean score on the worst pain experienced in the past week was $5.8($ median $=7)$ at baseline, and $4.8($ median $=5)$ after 60 days of treatment.

An increase in pain was associated with a decrease in total overall HRQoL, consistent with the results listed in Table 1. It was estimated that the treatment was able to increase the overall HRQoL score in 5.5 points, regardless of the variation in pain. It was also estimated that a decrease of one point in the score of the worst pain experienced in the past week was associated with an increase of 0.53 point in the mean overall HRQoL. 


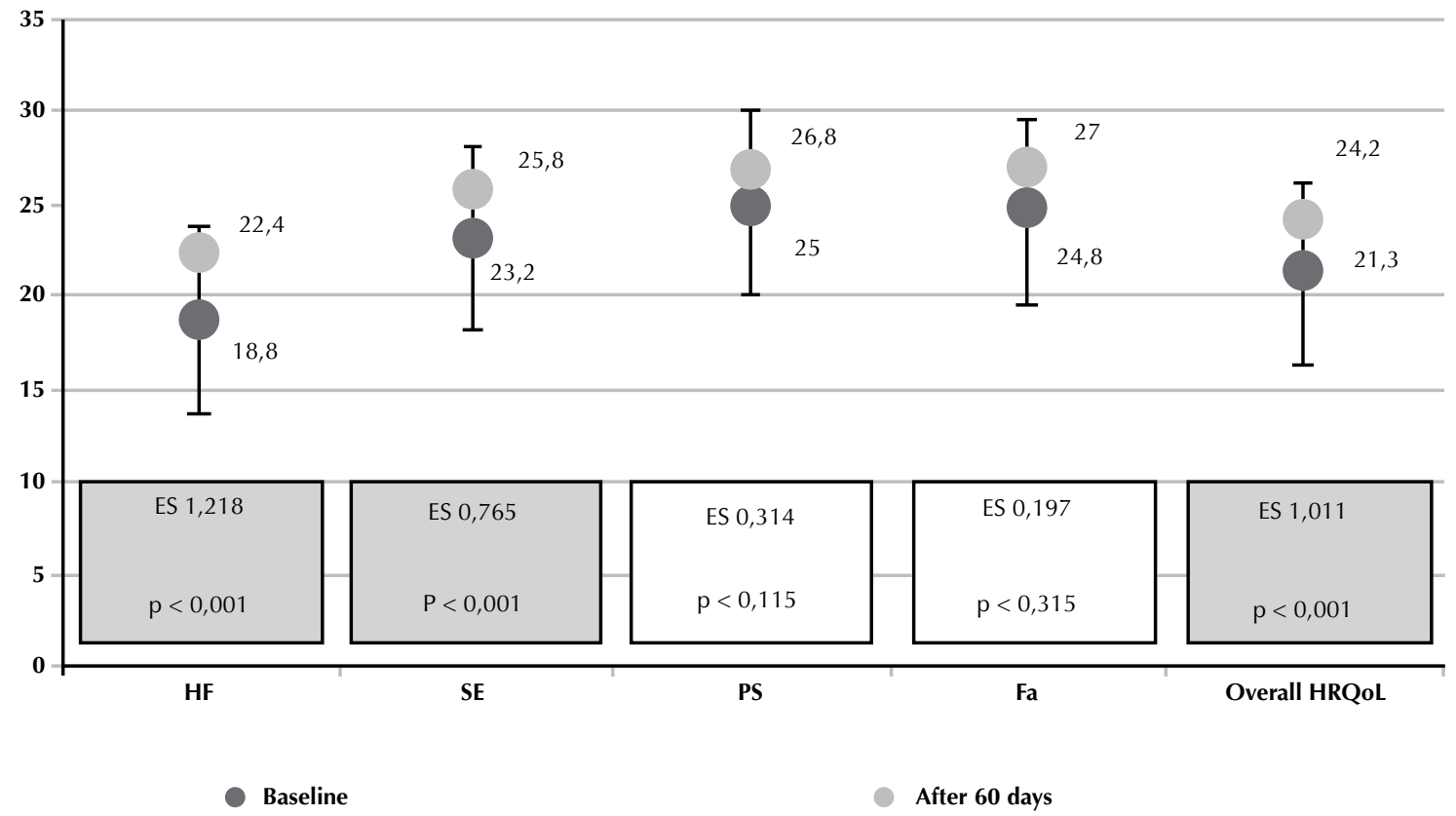

Figure 1 - Mean overall HRQoL and subscale scores on the Ferrans and Powers Quality of Life Index-Wound Version (FPQLI-WV) at baseline and after 60 days of treatment - São Paulo/Manaus, Brazil, 2013. ES = effect size; $P=$ probability value; $H F=$ health and functioning subscale; $\mathrm{SE}=$ socioeconomic subscale; $\mathrm{PS}=$ psycological and spiritual subscale; $\mathrm{Fa}=$ family subscale; and $\mathrm{Overall} \mathrm{HRQ}$ ( $=$ Overall health-related quality of life score.

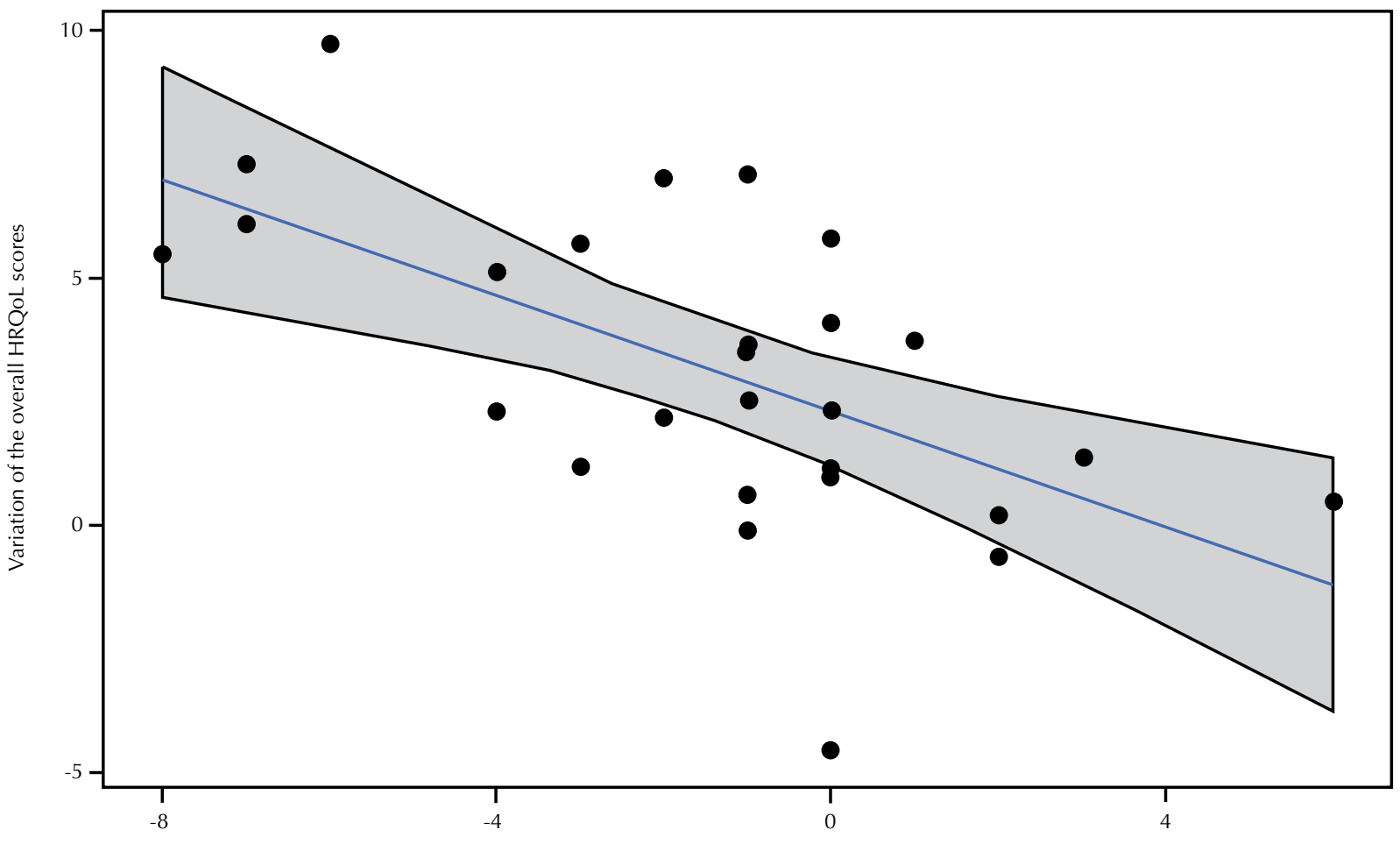

The worst pain experienced in the past week

Figure 2 - Scatter plot of the variation of the worst pain experienced in the past week and variation of the overall HRQoL scores at the 60-day follow-up - São Paulo/Manaus, Brazil, 2013.

After 60 days of treatment, $7.4 \%, 63 \%$ and $29.6 \%$ of patients reported small, medium and large changes, respectively, in the wound condition. During this period, the MID for the total FPQLI-WV score was 2.4, ranging from 1.9 to 4.2 across subscales (Table 1 ).

In addition, $40.7 \%, 18.5 \%$ and $18.5 \%$ of patients reported small, medium and large changes, respectively, in overall
HRQoL score associated with pain intensity in the past week, the rest of the patient didn't refer change in pain intensity. The MID for the overall HRQoL was 2.9 at the 60-day follow-up (Table 2).

Also, 38.5\%, $17.9 \%$ and $10.3 \%$ patients reported small, medium and large changes, respectively, in overall HRQoL score associated with rate of wound healing, 
the rest of the patient didn't reported change in wound healing rate. The MID for the overall HRQoL was 2.4 at 60 days, which is a value similar to those of other anchors (Table 3).

Table 1 - Minimal important difference (MID) for the overall HRQoL and subscale scores on the FPQLI-WV after 60 days of treatment, according to the Global Assessment Scale - São Paulo/Manaus, Brazil, 2013.

\begin{tabular}{|c|c|c|c|c|c|c|}
\hline \multirow{4}{*}{ FPQLI-WV } & \multicolumn{6}{|c|}{ Global changes between baseline and endpoint } \\
\hline & \multicolumn{2}{|c|}{ Small change } & \multicolumn{2}{|c|}{ Medium change } & \multicolumn{2}{|c|}{ Large change } \\
\hline & \multicolumn{2}{|c|}{$\mathrm{n}=2(7.4 \%)$} & \multicolumn{2}{|c|}{$\mathrm{n}=17(63 \%)$} & \multicolumn{2}{|c|}{$\mathrm{n}=8(29.6 \%)$} \\
\hline & Mean \pm SD & $95 \% \mathrm{Cl}$ & Mean \pm SD & $95 \% \mathrm{Cl}$ & Mean \pm SD & $95 \% \mathrm{Cl}$ \\
\hline Overall HRQoL & $2.4 \pm 2.0$ & {$[-0.4-5.1]$} & $3.3 \pm 2.6$ & {$[2.0-4.5]$} & $4.0 \pm 2.6$ & {$[2.2-5.8]$} \\
\hline Health/ Functioning & $4.2 \pm 1.9$ & {$[1.6-6.8]$} & $4.0 \pm 3.3$ & {$[2.5-5.6]$} & $5.6 \pm 3.3$ & {$[3.3-7.9]$} \\
\hline Socioeconomic & $1.9 \pm 2.1$ & {$[1.0-4.8]$} & $2.5 \pm 2.3$ & {$[1.3-3.7]$} & $3.8 \pm 2.6$ & {$[2.0-5.6]$} \\
\hline Psychological/ Spiritual & $2.2 \pm 1.8$ & {$[-0.3-4.6]$} & $3.6 \pm 3.7$ & {$[1.8-5.3]$} & $1.9 \pm 2.1$ & {$[0.5-3.4]$} \\
\hline Family & $0 \pm 0$ & {$[0-0]$} & $2.9 \pm 4.3$ & {$[0.9-4.9]$} & $1.9 \pm 3.2$ & {$[-0.3-4.2]$} \\
\hline
\end{tabular}

FPQLI-WV = Ferrans and Powers Quality of Life Index-Wound Version; Overall HRQoL score = Overall health-related quality of life score; SD = standard deviation and $\mathrm{CI}=$ confidence interval.

Table 2 - Minimal important difference (MID) for the overall HRQoL and subscale scores on the FPQLI-WV associated with the worst pain in the past week, after 60 days of treatment - São Paulo/Manaus, Brazil, 2013.

\begin{tabular}{|c|c|c|c|c|c|c|}
\hline \multirow{4}{*}{ FPQLI-WV } & \multicolumn{6}{|c|}{ Worst pain in the past week between baseline and endpoint } \\
\hline & \multirow{2}{*}{\multicolumn{2}{|c|}{$\begin{array}{c}\text { Small change } \\
\mathrm{n}=11(40.7 \%)\end{array}$}} & \multirow{2}{*}{\multicolumn{2}{|c|}{$\begin{array}{c}\text { Medium change } \\
\mathrm{n}=5(18.5 \%)\end{array}$}} & \multirow{2}{*}{\multicolumn{2}{|c|}{$\begin{array}{l}\text { Large change } \\
n=5(18.5 \%)\end{array}$}} \\
\hline & & & & & & \\
\hline & Mean \pm SD & $95 \% \mathrm{Cl}$ & Mean \pm SD & $95 \% \mathrm{Cl}$ & Mean \pm SD & $95 \% \mathrm{Cl}$ \\
\hline Overall HRQoL & $2.9 \pm 2.4$ & {$[1.5-4.3]$} & $3.1 \pm 2.1$ & {$[1.3-4.9]$} & $5.4 \pm 3.4$ & {$[2.4-8.4]$} \\
\hline Health/ Functioning & $4.4 \pm 3.0$ & {$[2.6-6.2]$} & $4.6 \pm 3.2$ & {$[1.8-7.4]$} & $6.0 \pm 5.0$ & {$[1.6-0.4]$} \\
\hline Socioeconomic & $2.4 \pm 1.8$ & {$[1.3-3.5]$} & $3.2 \pm 3.3$ & {$[0.3-6.1]$} & $5.0 \pm 2.6$ & {$[2.7-7.3]$} \\
\hline Psychological/ Spiritual & $2.0 \pm 1.8$ & {$[0.9-3.1]$} & $0.4 \pm 0.5$ & {$[0.0-0.8]$} & $5.8 \pm 3.2$ & {$[3.0-8.6]$} \\
\hline Family & $1.9 \pm 2.6$ & {$[0.4-3.4]$} & $0.2 \pm 0.4$ & {$[-0.2-0.6]$} & $3.8 \pm 5.1$ & {$[-0.7-8.3]$} \\
\hline
\end{tabular}

FPQLI-WV = Ferrans and Powers Quality of Life Index-Wound Version; Overall HRQoL score = Overall health-related quality of life score; SD = standard deviation and $\mathrm{CI}=$ confidence interval.

Table 3 - Minimal important difference (MID) for the overall HRQoL and subscale scores on the FPQLI-WV associated with the rate of wound healing, after 60 days of treatment - São Paulo/Manaus, Brazil, 2013.

\begin{tabular}{|c|c|c|c|c|c|c|}
\hline \multirow{4}{*}{ FPQLI-WV } & \multicolumn{6}{|c|}{ Rate of Wound Healing } \\
\hline & \multirow{2}{*}{\multicolumn{2}{|c|}{$\begin{array}{c}\text { Small change } \\
\mathrm{n}=15(38.5 \%)\end{array}$}} & \multirow{2}{*}{\multicolumn{2}{|c|}{$\begin{array}{l}\text { Medium change } \\
n=7(17.9 \%)\end{array}$}} & \multirow{2}{*}{\multicolumn{2}{|c|}{$\begin{array}{l}\text { Large change } \\
n=4(10.3 \%)\end{array}$}} \\
\hline & & & & & & \\
\hline & Mean \pm SD & $95 \% \mathrm{Cl}$ & Mean \pm SD & $95 \% \mathrm{Cl}$ & Mean \pm SD & $95 \% \mathrm{Cl}$ \\
\hline Overall HRQoL & $2.4 \pm 2.0$ & {$[1.4-3.4]$} & $1.8 \pm 1.1$ & {$[1.3-4.9]$} & $3.3 \pm 2.7$ & {$[0.7-5.9]$} \\
\hline Health/ Functioning & $3.5 \pm 3.4$ & {$[1.8-5.2]$} & $2.8 \pm 1.4$ & {$[1.8-3.8]$} & $4.4 \pm 3.4$ & {$[1.1-7.7]$} \\
\hline Socioeconomic & $1.8 \pm 1.6$ & {$[1.0-2.6]$} & $0.9 \pm 1.3$ & {$[-0.1-1.9]$} & $2.6 \pm 0.9$ & {$[1.7-3.5]$} \\
\hline Psychological/ Spiritual & $1.5 \pm 2.6$ & {$[0.3-2.7]$} & $1.7 \pm 1.8$ & {$[0.4-3.0]$} & $2.6 \pm 2.5$ & {$[0.2-5.0]$} \\
\hline Family & $1.6 \pm 3.0$ & {$[0.2-3.0]$} & $1.2 \pm 2.4$ & {$[-0.6-3.0]$} & $2.2 \pm 3.1$ & {$[-0.8-5.2]$} \\
\hline
\end{tabular}

FPQLI-WV = Ferrans and Powers Quality of Life Index-Wound Version; Overall HRQoL score = Overall health-related quality of life score; $\mathrm{SD}=$ standard deviation and $\mathrm{CI}=$ confidence interval.

\section{DISCUSSION}

Patients with chronic wounds receiving specialized outpatient treatmenthad a substantialimprovement in HRQoL after 60 days of treatment, as indicated by significant differences of large magnitude in effect size and a significant increase in overall HRQoL and subscale scores, especially on the health/functioning and socioeconomic subscales of the FPQLI-WV, between baseline and endpoint. No significant increase in the psychological/spiritual and family subscale scores was detected between the two time points, probably because patients had already reported high scores on these subscales at baseline.
The relationship between HRQoL and presence of chronic wounds, suggested by this study, has been described in the literature ${ }^{(1,4,21)}$. The difficulty of assessing HRQoL in patients with chronic wounds is a challenge to health professionals because of the specific health needs of this population. In wound care, this difficulty has been minimized due to the availability of specific assessment tools, such as the FPQLI-WV ${ }^{(11)}$, which is available only in Brazilian Portuguese.

In Brazil, there are only few studies that used the FPQLI-WV to evaluate HRQoL. In a cross-sectional study, it was found that the majority $(80 \%)$ of patients with 
leg ulcers had HRQoL scores $>20$, meaning good to very good HRQoL ${ }^{(22)}$. Low scores were reported in the health/ functioning subscale (consistent with the present study), as well as in the psychological/spiritual subscale ${ }^{(22)}$. The items related to the presence of a wound and healing time obtained the lowest scores, indicating a negative impact of the wound on HRQoL ${ }^{(22)}$.

Pain also has been described as a negative factor affecting HRQoL ${ }^{(23-24)}$. In this study, patients reported a decrease in the worst pain experienced in the past week from 5.8 at baseline to 4.8 after 60 days of treatment. In the multivariate regression model, this variable remained as a predictor of negative changes in overall $\mathrm{HRQ} \mathrm{OL}$ of patient with chronic wounds, and also in three of the four FPQLI-WV subscales, which is in agreement with the literature ${ }^{(2,23)}$.

In study also on generic QoL of patients with chronic venous ulcers, pain was present in $65.9 \%$ of cases, and absence of pain was considered a very important factor for the HRQoL of these patients ${ }^{(1)}$. Despite the need to listen and value the complaints about pain in patients with wounds, this procedure is still neglected by nurses during the assessment of patients, as shown in a study with 21 nurses working in the prevention and treatment of chronic wounds, where $90 \%$ of them didn't propose nursing intervention for pain control and only $10 \%$ investigated and considered pain as an outcome measure for interventions ${ }^{(25)}$.

The MID of 2.9 for the worst pain and wound healing rate in the past week was associated with a variation 2.4 points in the overall HRQoL score. Although the MID only measures the magnitude of changes, without indicating their direction, other results revealed an improvement in both the overall HRQoL and subscale scores on the FPQLI-WF, corresponding to a positive perception of patients also due to the pain reduction. The MID for the rate of wound healing was calculated despite the fact that this variable was not found to be a predictor of changes in the HRQoL of patients with chronic wounds. Knowing the minimum change in wound healing significant for the patient is of great importance as a reference for the establishment of therapeutic goals with a focus on the patient's HRQoL.

Religious practice associated with the family subscale was also a predictor of changes in HRQoL. This factor was not included as an anchor in the MID estimates because it is a non-measurable value. In a study on HRQoL in patients with leg ulcers, the item assessing faith in God had the highest mean score among the items on the FPQLI-WF ${ }^{(22)}$. Significant evidence of a positive association between quality of life and spiritual well-being has been found in different populations ${ }^{(26)}$. Faith is a constructive way of thinking ${ }^{(27)}$ and acts as a positive element in the coping process. In this context, religious coping is interpreted as a strategy used to deal with uncertainties associated with the disease and overcome crises ${ }^{(28)}$.

In this study, small variations in family subscale scores were observed between baseline and endpoint, but it is important to note that patients had already reported high scores on this subscale at baseline. The stability of the scores over time and their magnitude show that the family, as a source of social support, is an important factor for the HRQoL in patients with chronic wounds. In a qualitative study ${ }^{(3)}$ it was observed that family relationships can provide support for coping with the disease and the family members can provide care and practical help for self-management. Family support results in reduced psychological distress for both the family and patient, minimizing changes in family relationships related to the chronic disease ${ }^{(3)}$.

The small sample size was the major limitation of this study. At the time of data collection, and still nowadays, there were scarce services that relied on standard protocols for the treatment of chronic wounds and care provided by WOC nurses or those specialized in dermatology, reflecting the small sample size.

Based on the completeness of care, the nurse will be able to develop interventions considering the complaints of pain, strengthening of religious coping and the inclusion of the family in the care plan to minimize the impact of a chronic wound on the HRQoL of these patients. The inclusion in the daily practice of the use of specific tools for assessing HRQoL as an indicator for interventions can be an important strategy for strengthening and establishment of specialized care.

\section{CONCLUSION}

The results showed that patients with chronic wounds receiving specialized care reported improvement in HRQoL, measured by the increase in overall HRQoL and subscale scores on the FPQLI-WV between baseline and endpoint. Pain and religious practice have emerged as predictors of changes in HRQoL, with pain associated with overall HRQoL and the health/functioning, psychological/spiritual, and socioeconomic subscales; and religious practice associated with the family subscale. The MID for the overall HRQoL was 2.4, 2.9 and 2.4 considering the wound condition, the worst pain experienced in the past week, and the rate of wound healing, respectively, as perceived by the patient during the study period.

\section{RESUMO}

Objetivo: Avaliar a qualidade de vida relacionada à saúde, seus fatores preditivos e a magnitude das mudanças na qualidade de vida de pessoas com feridas crônicas em tratamento ambulatorial especializado. Método: Estudo secundário, retrospectivo, descritivo, quantitativo, realizado com pacientes atendidos em dois serviços ambulatoriais especializados no Brasil, os quais foram entrevistados no momento inicial e após 60 dias de tratamento pelos questionários Índice de Qualidade de Vida de Ferrans \& Powers - Versão Feridas, Escala Numérica de Dor, Escala de Avaliação Global de Mudança, Pressure Ulcer Scale for Healing e dados sociodemográficos e clínicos. Os dados foram analisados por meio de coeficiente de Spearman, teste de Mann-Whitney e regressão linear. Resultados: O estudo foi composto por 27 pacientes. Houve melhora na qualidade de vida após 60 dias de tratamento nas dimensões Saúde e Funcionamento e 
Socioeconômica. A redução da dor constituiu um fator preditor de mudança na qualidade de vida total, assim como a prática religiosa no domínio Família. 92,6\% dos pacientes perceberam mudança de moderada a grande na qualidade de vida. Conclusão: Houve melhora da qualidade de vida relacionada à saúde para a amostra estudada no período; dor e prática religiosa emergiram como preditores de mudanças na qualidade de vida relacionada à saúde.

\section{DESCRITORES}

Qualidade de Vida; Ferimentos e Lesões; Dor; Religião; Cuidados de Enfermagem.

\section{RESUMEN}

Objetivo: Evaluar la calidad de vida relacionada con la salud, sus factores predictivos y la magnitud de los cambios en la calidad de vida de personas con heridas crónicas en tratamiento de ambulatorio especializado. Metodología: estudio secundario, retrospectivo, descriptivo, cuantitativo, compuesto de 27 pacientes atendidos en dos servicios de ambulatorio especializados en Brasil que fueron entrevistados en el momento inicial y luego de 60 días de tratamiento mediante los cuestionarios Índice de Calidad de Vida de Ferrans \& Powers - Versión Heridas, Escala Numérica de Dolor, Escala de Evaluación Global de Cambio, Pressure Ulcer Scale for Healing y datos sociodemográficos y clínicos. Los datos fueron analizados mediante el coeficiente de Spearman, prueba de Mann-Whitney y regresión lineal. Resultados: hubo mejora en la calidad de vida tras 60 días de tratamiento en las dimensiones Salud y Funcionamiento y Socioeconómica. La reducción del dolor constituyó un factor predictor de cambio en la calidad de vida total, así como la práctica religiosa en el dominio Familia. E1 92,6\% de los pacientes percibieron cambio de moderado a grande en la calidad de vida. Conclusión: Hubo mejora de la calidad de vida relacionada con la salud para la muestra estudiada en el período; dolor y práctica religiosa emergieron como predictores de cambios en la calidad de vida relacionada con la salud.

\section{DESCRIPTORES}

Calidad de Vida; Heridas y Traumatismos; Dolor; Religión; Atención de Enfermería.

\section{REFERENCES}

1. Yamada BFA, Santos VLCG. Quality of life of individuals with chronic venous ulcers. Wounds. 2005;17(7):178-89.

2. Silva LLDA, Trevisan MJ, Carmo CRML. Qualidade de vida dos portadores de ferida em membros inferiores: úlcera de perna. Cienc Enferm. 2008; 14(1):43-52.

3. Waidman MAP, Rocha SC, Correa JL, Brischiliari A, Marcon SS. Daily routines for individuals with a chronic wound and their mental health. Texto Contexto Enferm. 2011;20(4):691-9.

4. Lopes CR, Figueiredo M, Ávila AM, Soares LMBM, Dionisio VC. Evaluation of limitations of venous ulcers in legs. JVasc Bras. 2013;12(1):5-9.

5. Franco CM, Franco TB. Linhas do cuidado integral: uma proposta de organização da rede de saúde [Internet]. 2012 [citado 2014 jun. 15]. Disponível em: http://www.saude.sp.gov.br/resources/humanizacao/homepage/acesso-rapido/formacao-tecnica-em-acolhimento-naatencao-basica/passo_a_passo_linha_de_cuidado.pdf

6. Terwee CB, Dekker FW, Wiersinga WM, Prummel MF, Bossuyt PMM. On assessing responsiveness of health-related quality of life instruments: guidelines for instrument evaluation. Qual Life Res. 2003;12(4):349-62.

7. Gold MR. Identifying and valuing outcomes. In: Haddix AC, Teutsch SM, Shafer PA, Dunet DO, editors. Prevention effectiveness: a guide to decision analysis. Oxford: Oxford University Press; 1996. p. 82-123.

8. Pereira EF, Teixeira CS, Santos A. Qualidade de vida: abordagens, conceitos e avaliação. Rev Bras Educ Fís Esporte. 2012;26(2):241-50.

9. Ferrans CE, Powers MJ. Quality of life index: development and psychometric properties. Adv Nurs Sci. 1985;8(1):15-24.

10. Ferrans CE, Powers MJ. Psychometric assessment of the Quality of Life Index. Res Nurs Health.1992;15(1):29-38.

11. Yamada BFA, Santos VLCG. Development and validation of Ferrans \& Powers Quality of Life Index: wound version. Rev Esc Enferm USP. 2009;43(n.spe):1105-13.

12. Cohen J. Statistical power analysis for the behavioral sciences. New York: Academic Press; 1977.

13. Hong F, Bosco JL, Bush N, Berry DL. Patient self-appraisal of change and minimal clinically important difference on the European organization for the research and treatment of cancer quality of life questionnaire core 30 before and during cancer therapy. BMC Cancer. 2013;13:165.

14. Oliveira AS. Índice de Qualidade de Vida Ferrans \& Powers - Versão Feridas: estudo da responsividade [tese doutorado]. São Paulo: Universidade de São Paulo, Escola de Enfermagem; 2012.

15. Carvalho DS, Kowac PA. A avaliação da intensidade de dor. Migrâneas Cefaleias. 2006;9(4):164-8.

16. Juniper EF, Guyatt GH, Willian A, Griffith LE. Determining a minimal important change in a disease-specific quality of life questionnaire. J Clin Epidemiol. 1994; 47(1):81-7.

17. Hollander M, Wolfe DA. Nonparametric statistical methods. New York: John Wiley and Sons; 1973.

18. Magalhães MN, Lima ACP. Noções de probabilidade e estatística. São Paulo: IME/USP; 2000.

19. Marquis P, Chassany O, Abertz L. A comprehensive strategy for the interpretation of quality-of-life data based on existing methods. Value Health. 2004;7(1):93-104

20. Wyrwich KW, Bullinger M, Aaronson N, Hays RD, Patrick DL, Symonds T. Estimating clinically significant differences in quality of life outcomes. Qual Life Res. 2005;14(2):285-95. 
21. Wachholz PA, Masuda PY, Nascimento DC, Taira CMH, Cleto NG. Quality of life profile and correlated factors in chronic leg ulcer patients in the mid-west of São Paulo State, Brazil. Anais Bras Dermatol. 2014;89(1):73-81.

22. Cardozo GM, Bermudes JPS, Araújo LO, Moreira ACMG, Ulbrich EM, Balduino AFA, et al. Contribuições da enfermagem para avaliação da qualidade de vida de pessoas com úlceras de perna. Rev Estima. 2012;10(2):19-27.

23. González-Consuegra RV, Verdú J. Quality of life in people with venous leg ulcers: an integrative review. J Adv Nurs. 2011;67(5):926-44.

24. Hopman WM, Buchanan Van Den Kerkhof EG, Harrison MB. Pain and health-related quality of life in people with chronic leg ulcers. Chronic Dis Inj Can. 2013;33(3):167-74.

25. Oliveira RA, Gualter WJS, Shaffe P, Silva VCF, Cesaretti IUR. Análise das intervenções de enfermagem adotadas para alívio e controle da dor em pacientes com feridas crônicas: estudo preliminar. Rev Estima [Internet]. 2005 [citado 2015 jun. 15];3(2). Disponível em: https:// www.revistaestima.com.br/index.php/estima/article/view/12/0

26. Peterman AH, Fitchett G, Brady MJ, Hernandez L, Cella D. Measuring spiritual wll-being in people with cancer: the functional assessment of chronic illness therapy-Spiritual Well-being Scale (FACIT-Sp). Ann Behav Med. 2002;24(1):49-58.

27. Castro SLS, Ferreira NMLA, Roque M, Souza MBB. Vivendo uma situação difícil: a compreensão da experiência da pessoa com úlcera venosa em membro inferior. Rev Estima. 2012;10(1):12-9.

28. Linard AG, Dantas FA, Silva RM. Women submitted to cervix uteri cancer treatment: how they cope with reality. Rev Bras Cancerol. 2002;48(4):493-8. 